\title{
Postnatal Changes in Transdiaphragmatic Pressure in Piglets
}

\author{
J. F. WATCHKO, D. E. MAYOCK, T. A. STANDAERT, AND D. E. WOODRUM \\ Department of Pediatrics, Division of Neonatal and Respiratory Diseases, University of Washington, \\ Seattle, Washington 98195
}

\begin{abstract}
We examined diaphragmatic force output in 25 anesthetized piglets ranging in postnatal age from 4 to 21 days (weight $1.3-4.0 \mathrm{~kg}$ ) in order to determine whether the diaphragm produces greater force output with maturation for a given level of neural input. Transdiaphragmatic pressure (Pdi) served as our index of diaphragmatic force output and was measured during "supramaximal" transvenous phrenic nerve stimulation at $100 \mathrm{~Hz}$ in order to control neural drive. Mean Pdi was $53 \pm 17 \mathrm{~cm} \mathrm{H}_{2} \mathrm{O}$ and ranged from a minimum of $29 \mathrm{~cm} \mathrm{H}_{2} \mathrm{O}$ to a maximum of $83 \mathrm{~cm} \mathrm{H} \mathrm{H}_{2} \mathrm{O}$. A significant positive correlation between Pdi and postnatal age was observed $(r=0.79, p<0.001)$. In addition, positive correlations were noted between Pdi and total body weight $(r=0.73, p<0.001)$ and Pdi and diaphragmatic wet weight $(r=0.77, p<0.001)$. The voltage needed to stimulate the phrenic nerves "supramaximally" did not correlate with postnatal age $(r=0.02, p=$ $0.16)$. We conclude that a developmental pattern of increasing Pdi with increasing postnatal age, total body weight, and diaphragmatic wet weight exists in piglets and occurs within the context of a controlled level of neural drive. (Pediatr Res 20: 658-661, 1986)
\end{abstract}

\section{Abbreviations}

Pdi, transdiaphragmatic pressure

Pga, gastric pressure

Pes, esophageal pressure

Pmo, mouth pressure

The human newborn (1-3), and the infant monkey, Macaca nemestrina (4), exhibit a marked increase in resting minute ventilation and tidal volume by the end of the first postnatal month when compared with values obtained during the $1 \mathrm{st}$ wk of life. The increase in these ventilatory parameters remain significant even after standardization for changes in body weight. The potential mechanisms modulating this increase in basal ventilation are unclear.

The postnatal ventilatory gain in the infant monkey is associated with an increase in inspiratory effort as determined by esophageal pressure changes (4). One could hypothesize that this finding reflects an increase in neuromuscular output. In support of this hypothesis are studies that document a postnatal increase in respiratory muscle force output $(5,6)$. However, no data exist to determine whether 1) the increase in inspiratory effort is of

Received December 27, 1985; accepted March 6, 1986

Address correspondence and reprint requests to Jon F. Watchko, M.D., Division of Neonatal and Respiratory Diseases, Department of Pediatrics RD-20, University of Washington, Seattle, WA 98195.

Supported in part by Public Health Service Grants NIH HL19187, and MCH 000955 . central origin and modulated by increased phrenic nerve activity or 2) whether the diaphragm provides greater force output with maturation for a given level of neural input. The latter might be expected to occur in light of reported developmental changes in both thoracoabdominal mechanics and the diaphragm (7).

We, therefore, hypothesized that the diaphragm provides greater force output with maturation for a given level of neural input. The current study examined diaphragmatic force output in piglets over a range of postnatal ages. Pdi served as our index of diaphragmatic force output and was measured during phrenic nerve stimulation in order to control neural drive.

\section{METHODS}

Farm-bred piglets obained from the University of Washington vivarium served as our study animal. Data are reported on 25 piglets ranging in postnatal age from 4 to 21 days (weight 1.3$4.0 \mathrm{~kg}$ ). The animals were anesthetized with an intravenous combination of chloralose $(50 \mathrm{mg} / \mathrm{kg})$ and urethane $(200 \mathrm{mg} /$ $\mathrm{kg}$ ) and studied in the supine position. Subsequent infusions of anesthesia were given if the piglet developed jaw clonus. Only anesthetized piglets with a respiratory rate of 15 to 30 breaths per min, a $\mathrm{PaO}_{2}>60$ torr in room air, and a $\mathrm{PaCO}_{2} \leq 50$ torr were studied. The trachea was surgically exposed and cut horizontally. A metal tube ( $6.35 \mathrm{~mm}$ OD) was inserted in the distal trachea, secured with suture, and attached to a Hans-Rudolph miniature one-way nonrebreathing valve (no. 2384). A femoral artery and vein were cannulated to monitor blood gases and give anesthesia. A Corning 168 Blood Gas Analyzer (Corning Glass Works, Medfield, MA) was utilized to determine arterial blood gas tensions. Rectal temperature was continuously monitored (YSI Tele-thermometer 43TA, Yellow Springs Instrument Co., Yellow Springs, $\mathrm{OH}$ ) and maintained between $38.5-39.5^{\circ} \mathrm{C}(8)$ by a radiant warmer. The animal preparation is schematically illustrated in Figure 1.

Pdi was measured with balloon tipped catheters in the Pga and middle third of the Pes (9). Thin walled latex balloons $(4.5 \mathrm{~cm}$ long, Young Rubber Corp., Trenton, NJ) containing $0.5 \mathrm{ml}$ of air were connected by means of polyvinyl catheters $(1.65 \mathrm{~mm}$ ID) to a differential pressure transducer (MP 45, Validyne, Northridge, CA) to obtain transdiaphragmatic pressure (Pdi = Pga - Pes). This transdiaphragmatic pressure measurement was obtained at end expiration with the trachea occluded (10).

The phrenic nerves were stimulated transvenously (11) by electrodes inserted into both external jugular veins. The electrode tips were positioned by initiating electrical signals from a nerve stimulator (Grass S48 Stimulator, Grass Medical Instruments, Quincy, MA) and advancing both catheters until the diaphragm contracted. Electrode position was further adjusted by advancing or withdrawing the catheters to produce a synchronous contraction of both diaphragmatic leaves. The nerve stimulator voltage was incrementally increased until there was no further increase in Pdi. The voltage was then increased by $20 \%$ to ensure a 


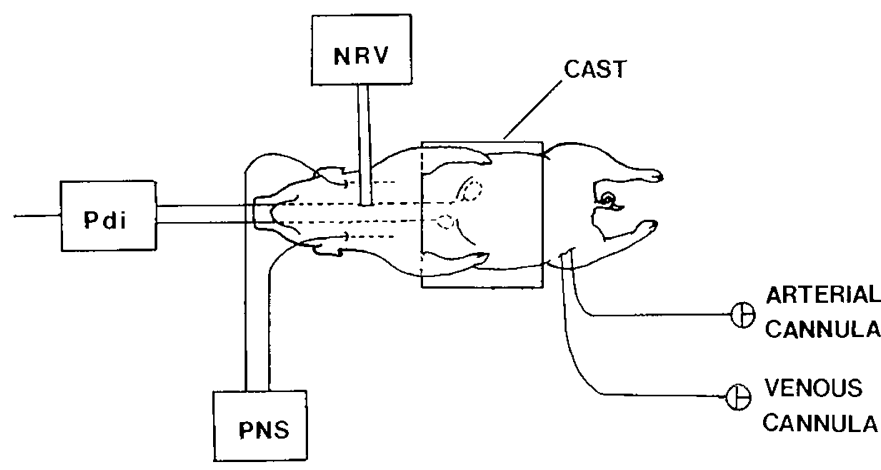

Fig. 1. Animal preparation. Piglet breathes spontaneously through a nonrebreathing valve $(N R V)$. Pdi is measured with two balloons and is the difference between Pga and Pes pressures. Electrodes for stimulation of phrenic nerves are attached to a peripheral nerve stimulator (PNS). Femoral artery and venous catheters as well as a plaster cast (CAST) covering the entire abdomen and lower third of the chest are in place. See text for additional details.

"supramaximal" stimulation and recorded. The electrodes were secured with suture. The Pdi generated with this supramaximal voltage at a frequency of $100 \mathrm{~Hz}$ served as our index of diaphragmatic force output. Voltage pulses were of $0.2 \mathrm{~ms}$ duration. Stimulation trains were applied for $2 \mathrm{~s}$. Measurements of Pdi were obtained in triplicate.

To ensure a consistency of diaphragmatic shortening, a preformed plaster cast covering the entire abdomen and lower third of the chest was applied during individual phrenic nerve stimulations in all piglets. Between phrenic nerve stimulations the piglets were allowed to breath unrestricted. The Pdi values reported herein represent baseline data obtained prior to studying the response of the piglet to various respiratory stimuli.

Pdi and total body weight measurements were obtained in all piglets. Total body weight was measured at the beginning of the study (uninstrumented animal) on a platform balance (Jacobs Brothers Co., New York, NY). Diaphragmatic wet weight measurements were obtained in 18 piglets following the completion of the study. These piglets were sacrificed with an overdose of pentobarbital and the diaphragm excised (with fat and tendon removed), blotted dry, and weighed on a triple beam balance (750 S, Ohaus, Florham Park, NJ).

Statistical analysis of the relationship between Pdi and postnatal age, body weight, and diaphragmatic weight in piglets was performed using correlation and regression analysis (Minitab Release 80.1, Penn State University, 1980).

\section{RESULTS}

Each Pdi reported is the mean of triplicate measurements. For the 25 piglets, mean Pdi was $53 \pm 17 \mathrm{~cm} \mathrm{H}_{2} \mathrm{O}$ and ranged from a minimum of $29 \mathrm{~cm} \mathrm{H}_{2} \mathrm{O}$ to a maximum of $83 \mathrm{~cm} \mathrm{H}_{2} \mathrm{O}$.

The developmental pattern of Pdi generation, considered as a function of postnatal age is seen in Figure 2. This plot documents a significant positive correlation between Pdi and postnatal age $(r=0.79, p<0.001)$. Similarly, the plot of Pdi and total body weight seen in Figure 3 documents a positive correlation between these two variables $(r=0.77, p<0.001)$. In addition, a positive correlation between Pdi and diaphragmatic wet weight was noted $(r=0.73, p<0.001)$ as seen in Figure 4. Phrenic nerve stimulation voltage $(8-12 \mathrm{~V})$ did not correlate with postnatal age $(r=$ $0.02, p=0.16)$.

\section{DISCUSSION}

The main finding of this study is that a developmental pattern of increasing Pdi with increasing postnatal age, body weight, and diaphragmatic weight exists in piglets, and occurs within the context of a controlled level of neural drive.

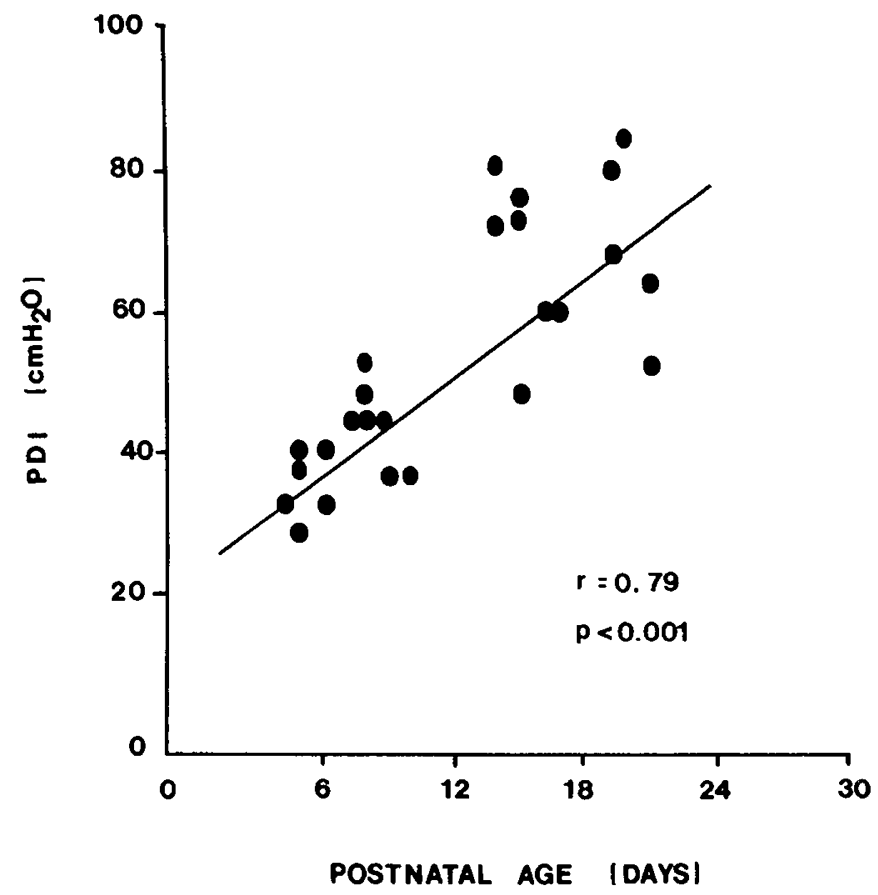

Fig. 2. Relationship between Pdi on the ordinate and postnatal age on the abscissa. The straight line is the linear regression through the data.

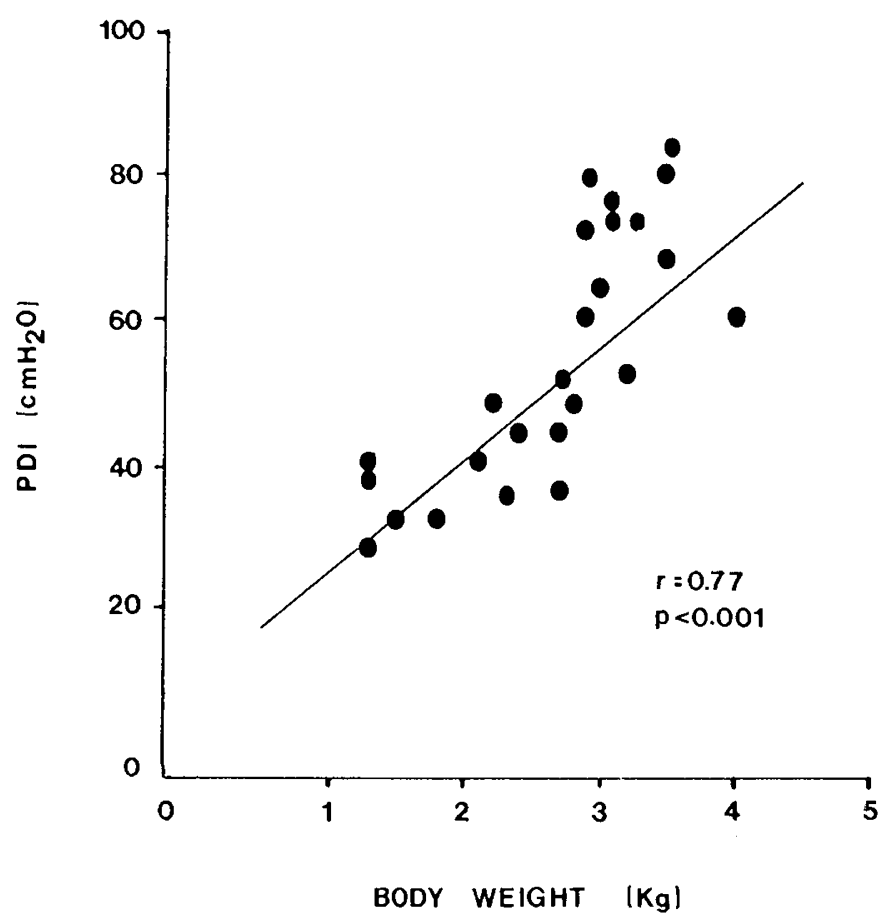

Fig. 3. Relationship between Pdi on the ordinate and total body weight on the abscissa. The straight line is the linear regression through the data.

\section{CRITIQUE}

The Pdi generated at any given level of electrical stimulation is affected by chest wall and diaphragmatic configuration (12). A major determinant of diaphragmatic geometry is lung volume. During phrenic nerve stimulation, lung volume was kept constant at fonctional residual capacity by occluding the trachea at end expiration. 


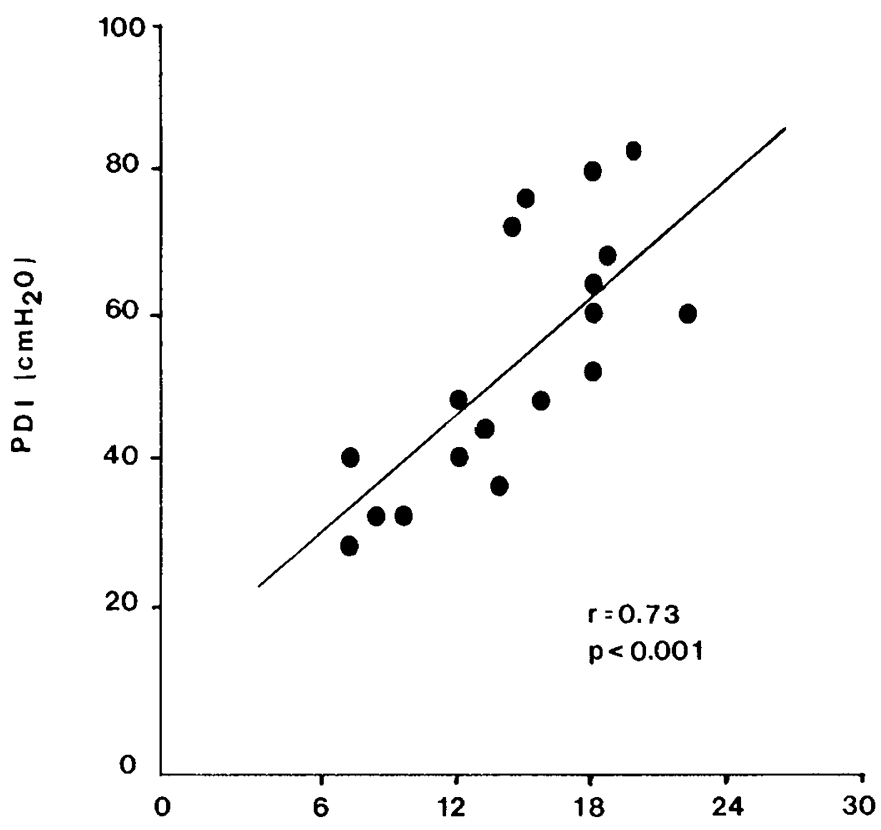

DIAPHRAGMATIC WEIGHT $|\mathrm{g}|$

Fig. 4. Relationship between Pdi on the ordinate and diaphragmatic wet weight on the abscissa. The straight line is the linear regression through the data.

Diaphragmatic contractions during phrenic nerve stimulation and airway occlusion, however, are not isometric. Recent evidence utilizing sonomicrometry indicates that the diaphragm shortens under such conditions (13). The degree of this diaphragmatic shortening is determined by the compliance of the abdominal wall (13). To ensure a constancy of abdominal configuration during phrenic nerve stimulation a rigid preformed plaster cast was placed snugly over the entire abdomen and lower third of the chest during individual phrenic nerve stimulations.

In this study Pdi was measured using the balloon-catheter technique. The in vivo accuracy of the esophageal estimate of pleural pressure was determined by comparing Pes and Pmo pressures during an occluded inspiratory effort in eight piglets (14). This "occlusion test" procedure yields a Pes/Pmo ratio that approaches unity if the Pes is accurate (14). In the supine position this ratio is almost always less than one (14). Results from our piglets studied in the supine position using the occlusion test technique show that Pes is generally within $85 \%$ of Pmo during inspiratory occlusions (Pes/Pmo $=0.86=/-0.06$ ). Importantly, in these animals, Pes/Pmo measurements obtained with occlusions during phrenic nerve stimulations give identical results. Thus, we believe that our Pdi measurement is a reliable index of diaphragmatic force output.

\section{DEVELOPMENTAL DIFFERENCES}

Out study documents a developmental pattern of increasing diaphragmatic force output. Specifically, Pdi increases significantly with increasing postnatal age, body weight, and diaphragmatic wet weight. Similar developmental patterns have been suggested by data collected from human infants $(5,6)$. Scott et al. (5) have shown a positive correlation between the maximal transdiaphragmatic pressure in infants during crying and postconceptual age, and Shoults et al. (6) have documented that maximal inspiratory force in neonates increases significantly with increasing gestational age. These clinical studies, however, do not control the constancy of central neural drive. In contrast, our piglet diaphragms were stimulated with a supramaximal phrenic nerve voltage to ensure a maximal force output for the given frequency of stimulation $(100 \mathrm{~Hz})$ and control neural drive.

Whether the observed postnatal gain in piglet diaphragmatic force output is entirely due to intrinsic properties of the diaphragm or is contributed to by changes in chest wall compliance and/or other factors cannot be determined from the available data. Existing experimental evidence and theoretical consideration, however, would suggest that developmental changes in 1) chest wall compliance $(15), 2$ ) the angle of diaphragmatic insertion (16), and 3) composition of the diaphragm (17) may all alter the force generating characteristics of this muscle.

In the neonate, the specific compliance of the rib cage is higher than the adult (15). Similar developmental changes in chest wall compliance occur in piglets (18). However, whether any significant change occurs over the age range represented by our piglets remains unknown. If a difference did exist, it is likely that the older piglet chest wall would be less compliant compared with its younger counterpart. This physical characteristic, all other factors being equal, might distribute diaphragmatic muscle force more effectively with less effort dissipated on a compliant chest wall during phrenic nerve stimulations, and, hence, provide a theoretical advantage in favor of generating a higher level of Pdi in older piglets. Indeed, LeSouef et al. (19) have documented that Pdi depends not only on the strength of the diaphragmatic contraction but also on the presence and degree of chest wall distortion (19). Specifically, they found that during minimal chest wall distortion, an increase in central neural drive produced an increase in Pdi; whereas when chest wall distortion was great, large increases in central neural drive produced no increase in Pdi. They concluded that chest wall distortion markedly limits the effectiveness of the diaphragm as a force generator. Thus, if a developmental decrease in chest wall compliance did occur in the piglet between 4 and 21 days of postnatal life, it would contribute to the observed postnatal gain in diaphragmatic force output.

A second more speculative developmental variant in neonatal thoracic anatomy has also been proposed (16). It is suggested that, in contrast to the oblique insertion angle of the adult diaphragm, the angle of insertion of the diaphragm is virtually horizontal in neonates. With this mechanical configuration, the diaphragm would descend less during contraction, thus increasing abdominal pressure to a lesser degree; the overall result was a decrease in diaphragmatic force output, rib cage expansion, and tidal volume per given neural stimulus to the diaphragm. Thus, it is possible that relative changes in gastric pressure could account for the changes in Pdi which we observed. We did not partition transdiaphragmatic pressure measurement into its abdominal and pleural components and data to support this interesting possibility have yet to be published.

The basis for the developmental response to the phrenic nerve stimulus over the age range studied could also lie in developmental changes intrinsic to the muscle itself. Progressive increases in the amount of contractile material, specifically, 1) myofibrillar number, 2) myofibrillar cross-sectional area, and 3) sarcomere number are known to occur with increasing postnatal age in skeletal muscle (17). These changes are functionally significant because each one individually contributes to the size of the muscle fiber, and thus enables the muscle to produce additional force (17). Corroborating this concept is the high correlation between Pdi and diaphragmatic wet weight seen in our piglets. Examination of piglet diaphragm muscle ultrastructure to determine developmental changes in its contractile material content has not been performed. In the absence of such data, changes in diaphragm muscle contractile material remains a tenable hypothesis to explain the developmental gain in force output during phrenic nerve stimulation seen in piglets.

In summary, the data collected in this investigation demonstrate a progressive increase in Pdi with increasing postnatal age, total body weight, and diaphragmatic wet weight. The functional importance and clinical relevance of this data remain uncertain. 
Nevertheless one could speculate that the observed developmental increase in force output generation potential (in absolute terms) would confer an advantage in defending ventilation when challenged with a respiratory load to the more mature subject. Recent short-term load response studies in neonates would support this hypothesis $(20,21)$. Longer term load studies, however, are required before definite conclusions are possible.

Acknowledgments. The authors thank Krishna Fells, Libby Acuna, and Richard Tuck for their help in completing these studies and Aileen O'Meara, Jo Ann Jarrett, and Peter Dapper for help in preparation of the manuscript

\section{REFERENCES}

1. Deming J, Hanner JP 1936 Respiration in infancy. I. A study of rate, volume, and character of respiration in healthy infants during the neonatal period. Am J Dis Child 51:823-831

2. Haddad GG, Epstein RA, Epstein MAF, Leistner HL, Marino PA, Mellins RB 1979 Maturation of ventilation and ventilatory pattern in normal sleeping infants. J Appl Physiol 46:998-1002

3. Rigatto H, Brady J, Dela Torre Verduzco R 1975 Chemoreceptor reflexes in preterm infants. I. The effect of gestational and postnatal age on the ventilatory response to inhalation of $100 \%$ and $15 \%$ oxygen. Pediatrics 55:604613

4. LaFrambiose WA, Tuck RE, Woodrum DE, Guthrie RD 1984 Maturation of eucapnic respiration in the neonatal monkey. Pediatr Res 18:943-948

5. Scott CB, Nickerson BG, Sargent CW, Platzker A, Warburton D, Keens TG 1982 Developmental pattern of maximal diaphragmatic pressure in infants during crying. Pediatr Res 17:707-709

6. Shoults D Clark TA, Benumof JL, Mannino FL 1979 Maximum inspiratory force in predicting successful neonate tracheal extubation. Crit Care Med 7:485-486

7. Watchko JF, Woodrum DE 1984 Neonatal respiratory failure: the role of the ventilatory pump. In: WA Hodson (ed) Seminars in Respiratory Medicine, Vol 6. Thieme-Stratton, Inc., New York, pp 135-140

8. Mount LE, Ingram DL 1971 Physiology. In: The Pig as a Laboratory Animal Academic Press, New York pp 65-78

9. Milic-Emili J, Mead J, Turner JM, Glauser EM 1964 Improved technique for estimating pleural pressure from esophageal balloons. J Appl Physiol 19:207211

10. Aubier M, Viires N, Murciano D, Medrano G, Lecoguic Y, Pariente R 1984 Effects and mechanism of action of terbutalene on diaphragmatic contractility and fatigue. J Appl Physiol 56:922-929

11. Planas RF, McBrayer RH, Koen PA 1985 Diaphragmatic pressure: transvenous vs. direct phrenic nerve stimulation. J Appl Physiol 59:269-273

12. Grassino A, Goldman MD, Mead J, Sears TA 1978 Mechanics of the human diaphragm during voluntary contraction: statics. J Appl Physiol 44:829-839

13. Newman S, Road J, Bellemare F, Clozel FP, Lavigne CM, Grassino A 1984 Respiratory muscle length measured by sonomicrometry. J Appl Physiol 56:753-764

14. Baydur A, Panagiotisk K, Beheragisk K, Zin WA, Jaeger M, Milic-Emili J 1982 A simple method for assessing the validity of the esophageal balloon technique. Am Rev Respir Dis 126:788-791

15. Agostoni E 1959 Volume-pressure relationships of the thorax and lung in the newborn. J Appl Physiol 14:909-913

16. Muller NL, Bryan AC 1979 Chest wall mechanics and respiratory muscles in infants. Pediatr Clin North Am 26:503-516

17. Goldspink G 1983 Alterations in myofibril size and structure during growth exercise, and changes in environmental temperature. In: Peachy LD, Adrian RH, Geieger SR (eds) Skeletal Muscle Handbook of Physiology. American Physiological Society, Bethesda, MD, pp 539-554

18. Koehler RC, Schlein CL, Michael JR, Chantojanasira T, Rodgers MC, Traystman RJ 1985 Age related changes in chest geometry during conventional cardiopulmonary resuscitation in piglets. Pediatr Res 19:139A

19. LeSouef PN, Lopes JM, England SJ, Bryan MH, Bryan AC 1983 Effect of chest wall distortion on occlusion pressure and the preterm diaphragm. $J$ Appl Physiol 55:359-364

20. LaFramboise WA, Standaert TA, Guthrie RD, Woodrum DE 1983 The response of the newborn vs. the mature infant monkey to external flow resistance. Physiologist 26:A95

21. Abbasi S, Duara S, Shaffer T, Fox WW 1984 Effect of external inspiratory loading on ventilation of premature infants. Pediatr Res 18:150-154 